\section{Pulsed Electric Field Processing: An Emerging Technology for Food Preservation}

\section{Mahendra Pal}

Ex-Professor of Veterinary Public Health, College of Veterinary Medicine, Addis Ababa University, Debre Zeit, Ethiopia

"Corresponding author: Mahendra Pal, Ex-Professor of Veterinary Public Health, College of Veterinary Medicine, Addis Ababa University, Debre Zeit, Ethiopia, Tel: 091-9426085328; E-mail: palmahendra2@gmail.com

Received date: March 16, 2017; Accepted date: April 28, 2017; Published date: May 5, 2017

Copyright: () 2017 Pal M. This is an open-access article distributed under the terms of the Creative Commons Attribution License, which permits unrestricted use, distribution, and reproduction in any medium, provided the original author and source are credited.

Abstract
In recent years, technological revolution, nutritional awareness, and continuous demand for new generation have
necessitated the search for new techniques of food processing in industries. Pulsed electric field is one of the
emerging techniques to preserve the foods, especially the liquid ones such as milk, yoghurt, juices, soups, rice
pudding, and liquid eggs, but not suitable for solid foods. It has the potential to produce the foods with excellent
sensory and nutritional quality besides extends shelf life and ensures safety. Pulsed electric field uses short electric
pulses to preserve the foods. This technology is best suited to pasteurize heat sensitive foods. It is hoped that India
has great opportunity to develop this novel technology for the food processing. Emphasis is given to undertake
comprehensive studies on the efficacy of pulsed electric field on various bacteria and fungi, which are associated
with spoilage of foods.

Keywords: Emerging technology; Foods; Preservation; Pulsed electric field processing; Milk; Yoghurt

\section{Introduction}

Since ancient time, humans have used methods to preserve the food for storing so that it can be used later to eat. A number of techniques such as pasteurization, drying, pickling, smoking, canning, irradiation, cooling, freezing, etc. are employed to preserve the foods from microbial spoilage that can result into economic loss as one fourth of world's food supply is lost. Spoiled food becomes inedible due to undesirable changes in the appearance, color, odor, flavor, and texture. Microbes are widely prevalent in the environment (air, water, soil) and can easily contaminate the food at any stage from farm to table. Hence, preservation of food is highly imperative to ensure the safety, prevent spoilage, extend shelf life, enhance keeping quality, control the food poisoning and reduce economic loss [1].

Presently, many non-thermal food processing technologies such as cold plasma, high pressure processing, irradiation, microwave heating, ohmic heating, pulsed high intensity light, pulsed x-rays, oscillating magnetic field, pulsed electric field, and high power ultrasonic are developed to improve, replace or complement the conventionally existing methods. These techniques are mostly employed for liquid foods as against solids ones, and are mostly used in large scale production. Further, the cost of equipment's used to impart nonthermal processing is high as compared to equipment's employed for conventional thermal processing. Out of several non-thermal processing methods, pulsed electric field is one of the most promising techniques, which can preserve the liquid foods by inactivation of microbes, and also retains the nutritional and sensory attributes of foods. This system is associated with minimum energy utilization and greater energy efficiency than thermal processing [2]. Pulsed electric field is considered superior to traditional heat treatment because it greatly minimizes the detrimental changes of the physical and sensory properties of food [3]. Furthermore, a consumer likes to purchase the processed food that gives fresh appearance. Application of pulsed electric field as a non-thermal method of food processing is gaining popularity. It kills the vegetative cells but the texture, color, flavor and nutrients of the food are maintained [3].

Pulsed electric field processing is suitable for the decontamination of heat sensitive foods. Furthermore, there is no environmental hazard, and there is no evidence of toxicity [2]. The major constraint to employ this technology on wider scale for the pasteurization of heat sensitive foods is high initial investment. The engineering aspects of pulsed electric field processing include bench top unit, lab scale pulser and treatment chamber. A pilot size pulser may cost approximately US Dollar 250,000. The other units of industrial use are available at the price of US Dollar 450,000 to 2,000,000 [2]. The aim of present communication is to delineate briefly the importance of pulsed electric field as novel method to preserve the foods.

\section{Principle of Pulsed Electric Field}

The basic principle of pulsed electric field is the application of short pulses of high electric fields with duration of micro seconds and intensity of $10-80 \mathrm{kV} / \mathrm{cm}$. The processing time is calculated by multiplying the number of pulses with effective pulse duration. The use of high voltage results in electric field that causes the inactivation of organisms. When an electric field is applied, electric current flows into the liquid food and is transferred to each point in the liquid because of charged molecules present [4]. It is imperative that after the treatment, the food must be aseptically packaged and properly stored under refrigeration to have long shelf life.

\section{Effect of Pulsed Electric Field on Microbial Inactivation}

Two mechanisms are proposed for the mode of action of pulsed electric field action on the microbial membrane of the organism. The first is electroporation in which the cell is exposed to high voltage electric field pulses that temporarily destabilizes the lipid bilayer and 
proteins of the cell membranes; and the second is electric breakdown. In both cases, the phenomenon starts by electroporation by which the cell wall is perforated and cytoplasmic contents leak out causing cell death $[5,6]$. A plethora of factors such as type of microorganisms, field intensity, pulse wave shape, conductivity of medium, $\mathrm{pH}$, treatment temperature, treatment time and energy input can affect the inactivation of microbes. Pulsed electric field shows lethal effects on vegetative bacteria, moulds and yeasts. However, resistance is observed in bacterial spores. Yeasts are more sensitive than bacteria. Further, Gram positive bacteria are more resistant to pulsed electric field than Gram negative organisms. This technology is effective to inactivate Bacillus subtilis in pea soup, Listeria innocua and L. monocytogenese in milk, Staphylococcus aureus in skim milk, Escherichia coli in liquid egg, Lactobacillus brevis in yoghurt and Saccharomyces cervisiae in apple juice $[7,3]$.

The inactivation of enzymes by pulsed electric field requires stronger electrical condition than microbial inactivation. It is important to mention that pulsed electric treatment at $21.5 \mathrm{kV} / \mathrm{cm}$ and high energy input reduced the lipase and peroxidase activity of raw milk by $65 \%$ and $25 \%$, respectively with negligible effect on alkaline phosphatase activity [8]. The other effects of this technology include extension of shelf life, retention of nutrients, improvement in quality and flavor, and high level of food safety.

\section{Application of Pulsed Electric Field for Food Processing}

In the modern time, the consumer demand has increased for minimally processed foods that have a more natural color and flavor. Currently, the application of pulsed electric field is gaining popularity as a non-thermal technology to preserve the original quality of foods as regards to texture, color, flavor, appearance besides nutritive values. Experience has shown that fresh look of the food product attracts the consumer to purchase it. Pulsed electric field is used to pasteurize variety of liquid and semisolid foods such as milk, yoghurt, apple juice, grape juice, orange juice, sugar cane juice, soups, brine solutions, liquid eggs [2,9-12]. This technology can be coupled with other processing methods, and can be used as a continuous process. It is very suitable for heat sensitive foods like juices and soups in order to prevent the loss of vitamins. It is important to mention that nutritional quality of milk remained unchanged after pulsed electric field treatment as there is no loss of vitamin $B_{1}$, vitamin $B_{2}$, vitamin $D$, and vitamin $E$ but vitamin $\mathrm{C}$ showed $93 \%$ retention.

Further, the color, moisture, fat content, titratable acidity, $\mathrm{pH}$, starter growth, rennet clotting time, cheese production and particle size were not affected by pulsed electric field treatment at field strength of $20-80 \mathrm{kV} / \mathrm{cm}$. The Yoghurt, flavoured milk, and yoghurt drinks when treated with pulsed electric field and heat increased the shelf life and also did not exhibit any change in sensory attributes of the products [12]. Presently, the preservation of liquid foods by pulsed electric field on pilot scale system is available in Germany, The Netherland, Sweden, and USA [2].

\section{Conclusion}

Pulsed electric field is a novel, non-thermal method of food preservation. Electric field strength and treatment are the most important factors involved in pulsed electric field technology. It is related to electromechanical instability of cell membrane. Pulsed electric field can be considered as a potential alternative to traditional thermal methods such as pasteurization. The effects of pulsed electric field on the nutritional and chemical aspects of foods should be further studied. Attempts should be made to develop some innovation to reduce the cost in pulsed electric field processing technique so that it can be widely used for preserving a wide variety of foods. There is a need to study the effect of pulsed electric field in combination with heat or other hurdles on the inactivation of bacterial spores in various types of foods.

\section{Acknowledgement}

I am very grateful to Prof. Dr. R. K. Narayan for going through the manuscript and Anubha for helping in computer work.

\section{References}

1. Pal M (2014) Preservation of various foods. Ph.D. Lecture Notes. Addis Ababa University, College of Veterinary Medicine, Debre Zeit, Ethiopia. Pp.1-11.

2. Kumar Y, Patel KK, Kumar K (2015) Pulse electric field processing in food technology. Int J Engg Stud Tech Approach 1: 6-17.

3. Kumar S, Agarwal N, Raghav PK (2016) Pulsed electric field processing: A review. Int J Eng Res Modern Edu 1: 111-118.

4. Zhang QH, Barbosa-Canovas GV, Swanson BG (1995) Engineering aspects of pulsed electric field pasteurization. J Food Engg 25: 261-181.

5. Tsong T (1990) Reviews on electroporation of cell membranes and some related phenomena. Bioelectrochemical and Bioenergetics 24: 271.

6. Martin-Belloso O, Elez-Martinez P (2005) Food safety aspects of pulsed electric field. In "Emerging Technologies for Food Processing". Edited by Da-Wen Sun. Elsevier Academic Press, London. Pp.184-217.

7. Reina LD, Jin ZT, Yosef AE, Zhang QH (1998) Inactivation of Listeria monocytogenese in milk by pulsed electric field. J Food Protection 61: 1203-1206.

8. Grahl T, Markl H (1996) Killing of microorganisms by pulsed electric fields. Applied Microbiol Biotech 45: 148-157.

9. Qin B, Pothakamury UR, Vega H, Martin O, Barbosa-Canvos GV, et al. (1975) Food pasteurization using high intensity pulsed electric fields. J Food Tech 49: 55-60.

10. Castro A, Barbosa-Canovas GV, Swanson BG (1993) Microbial inactivation of foods by pulses electric fields. J Food Processing Preservation 17: 47-73.

11. Barsotti L, Cheftel JC (1999) Food processing by pulsed electric fields. II Biological aspects. Food Review Int 15: 181-213.

12. Yeom HW, Evrendilek GA, Jin ZT, Zhang QH (2007) Processing of yoghurt based products with pulse electric field: microbial, sensory and physical evaluations. J Food Process Preserv 28: 161-178. 